\title{
Performance evaluation of the effectiveness of the use of core drivers in the construction of base plates
}

\author{
Dmitriy Chunyuk $^{1^{*}}$, Artem Selviyan ${ }^{2}$ and Serafima Selviyan ${ }^{1}$ \\ ${ }^{1}$ Moscow State University of Civil Engineering, Yaroslavskoe shosse, 26, Moscow, 129337, Russia \\ ${ }^{2}$ Open company "Iskon-project", Moscow, Russian Federation
}

\begin{abstract}
This article is an example of the calculation of a foundation monolithic slab using void formers during the construction of an apartment complex consisting of three buildings located on one stylobation. The issue of economy in the construction of a hollow core base slab compared to a solid one, by reducing the volume of concrete and reinforcement due to the location of liners in the neutral zone of concrete, is considered. At the same time, the bearing capacity and rigidity of the structure should remain at the same level.
\end{abstract}

\section{Introduction}

The first mentions concerning the use of void formers in the construction of floors, appeared at the beginning of the twentieth century, around 1905. [1] At present, both in our country and abroad, builders have begun to show interest in the construction of hollow core slabs with hollow cores.

In some European countries, innovative formwork with void formers has already been successfully implemented and used for the construction of lightweight floor slabs. One of such systems for the development and application of formwork are Cobiax (Switzerland) void-forming balls or ellipsoids; Nautilus (Spain) - prismatic empty elements. At the same time, such an overlap not only reduces the mass by $20-40 \%$ than a solid plate, but also has greater rigidity and carrying capacity. This is due to the fact that a large part of the concrete of the middle zone is withdrawn from the monolithic slab and is replaced by hollow liners. [2]

Due to the reduction in the mass of overlap, the consumption of concrete and reinforcement in columns and foundations is reduced. In comparison with the beam or captive solution of floor slabs, the construction height of the ceiling is reduced, which during the operation of the building reduces the cost of heating, ventilation and air conditioning.

The following requirements are imposed on of void formers:

\footnotetext{
* Corresponding author: chunyuk@mail.ru
} 
1. The own weight of the liner must be less than the weight of the concrete being expelled;

2. The cost of the liner must be less than or equal to the cost of the concrete being expelled;

3. The strength of the liner should ensure manufacturability of its application. That is, to have strength, allowing workers to freely move on them during the work;

4. Must have water resistance, frost resistance, heat resistance and UV resistance;

5. To meet sanitary standards.

A void formers can be made of the following materials:

1. Plastic

2. Foam plastic

3. Cardboard

4. Plywood

5. Foam concrete

The dimensions and geometry of the void formers are chosen based on the dimensions of the plate and its thickness according to the technological and structural requirements. The shape of the holders is varied: oval or round cylinders, spherical and ellipsoidal, as well as prismatic.

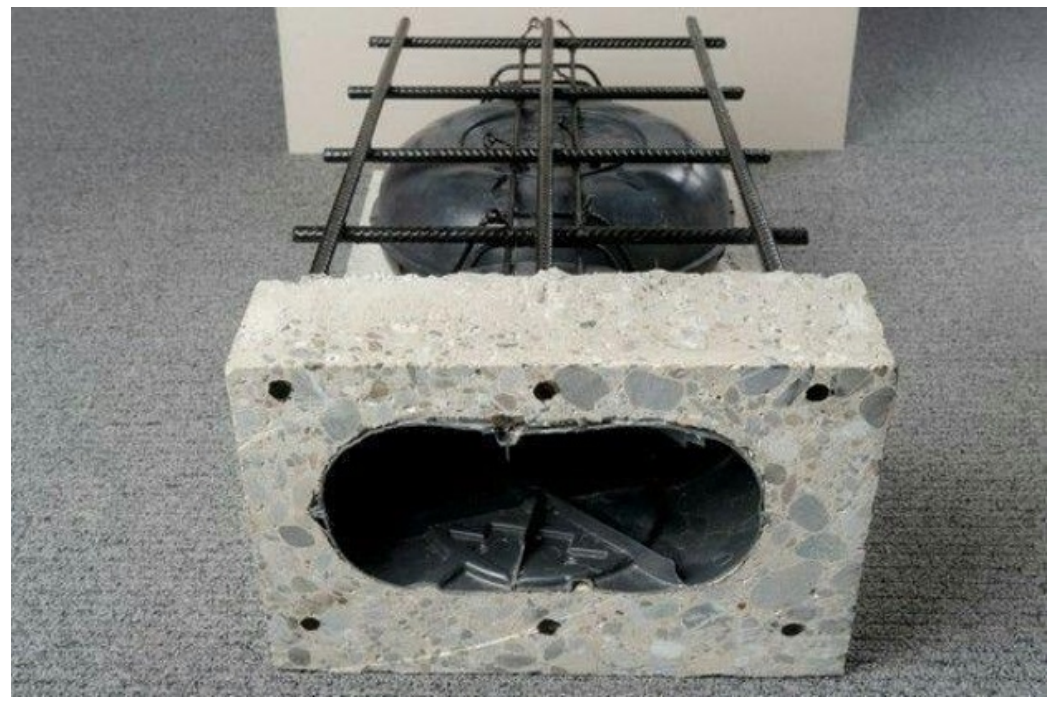

Fig. 1. Fragment of a slab with a void formers Cobiax

Builders and designers at the moment, unfortunately, undeservedly pay little attention to the possibility of using void formers in foundations.

This article has considered the possibility of using void formers in the construction of the base plate of the middle part of the stylobate of an apartment complex, located at: Moscow region, Odintsovsky district, D. Razdory, ter. Myakinino out of bounds, 1 turn, 1 stage.

The aim of the work was to compare the results of the calculation of a monolithic stylobation plate with a thickness of $1 \mathrm{~m}$ and the foundation with the use of void formers.

\section{Description of the complex}

The apartment complex consists of 3 high-rise buildings located on the common stylobate, which has two underground levels.

Complex dimensions: $74.3 \times 171.2 \mathrm{~m}$ 
The dimensions of the buildings: building $1-23.2$ x $51.3 \mathrm{~m}$, building $2-23.2 \times 59.4 \mathrm{~m}$, building 3 - 23.2 x $49.8 \mathrm{~m}$.

Number of floors in each building: lower mark 0.000 - 3 floors, above ground - 34 floors and 1 technical floor.

The height of the buildings of the complex with the inclusion of the upper technical floors is $105.9 \mathrm{~m}$.

\section{Engineering-geological conditions of the pad}

The geology of the field is represented by the following sediments: topsoil, modern modern floodplain alluvial deposits, Upper Quaternary deposits of the floodplain terraces of the Moscow River and Upper Jurassic rocks.

Modern floodplain alluvial deposits are mainly represented by small and medium sized sands, less often coarse and gravelly. The settlement thickness is $1.3-22.7 \mathrm{~m}$.

The Upper Quaternary deposits of the floodplain terrace are represented mainly by sands from dusty to medium size of medium density and dense, moist and saturated with water. Settlement thickness from 1.4 to $24.9 \mathrm{~m}$

The deposits of the Jurassic system underlying the Quaternary stratum are represented mainly by loams and clays of a refractory and semi-solid consistency. The thickness of the layer ranges from 0.25 to $16.8 \mathrm{~m}$. limits:

The main mechanical characteristics according to triaxial tests lie within the following

Modern alluvial floodplain deposits:

$\mathrm{E}=29-36 \mathrm{MPa} ; \varphi=35-39^{\circ} ; \mathrm{C}=1-2 \mathrm{kPa} ; v=0.3 ; \gamma=1.5-1.77 \mathrm{~g} / \mathrm{cm}^{3}$

Upper Quaternary alluvial deposits:

$\mathrm{E}=25-40 \mathrm{MPa} ; \varphi=31-38^{\circ} ; \mathrm{C}=1-3 \mathrm{kPa} ; v=0.29 ; \gamma=1.88 \mathrm{~g} / \mathrm{cm}^{3}$

Deposits of the Jurassic system:

$\mathrm{E}=16-25 \mathrm{MPa} ; \varphi=35-39^{\circ} ; \mathrm{C}=1-2 \mathrm{kPa} ; v=0.33 ; \gamma=2.71 \mathrm{~g} / \mathrm{cm}^{3}$

\section{Features of constructive solutions}

Load carrying structure - monolithic reinforced concrete braced frame, consisting of loadbearing walls, pylons and flat floor slabs.

The foundation is monolithic slabs with a thickness of 1 to $1.5 \mathrm{~m}$.

Interfloor overlappings - monolithic 220, $300 \mathrm{~mm}$ thick.

The stylobate cover plates are flat with capitals $350 \mathrm{~mm}$ thick. The size of capitals in the plan is $3.0 \times 3.0 \mathrm{~m}$.

The outer walls of the basement are monolithic reinforced concrete $300 \mathrm{~mm}$ thick.

Bearing frame material:

- concrete of strength class B35, waterproof W6, frost resistance F 50.

- fittings of class A500S (GOST R 52544 - 2006) and A240 (GOST 5781 - 82). 


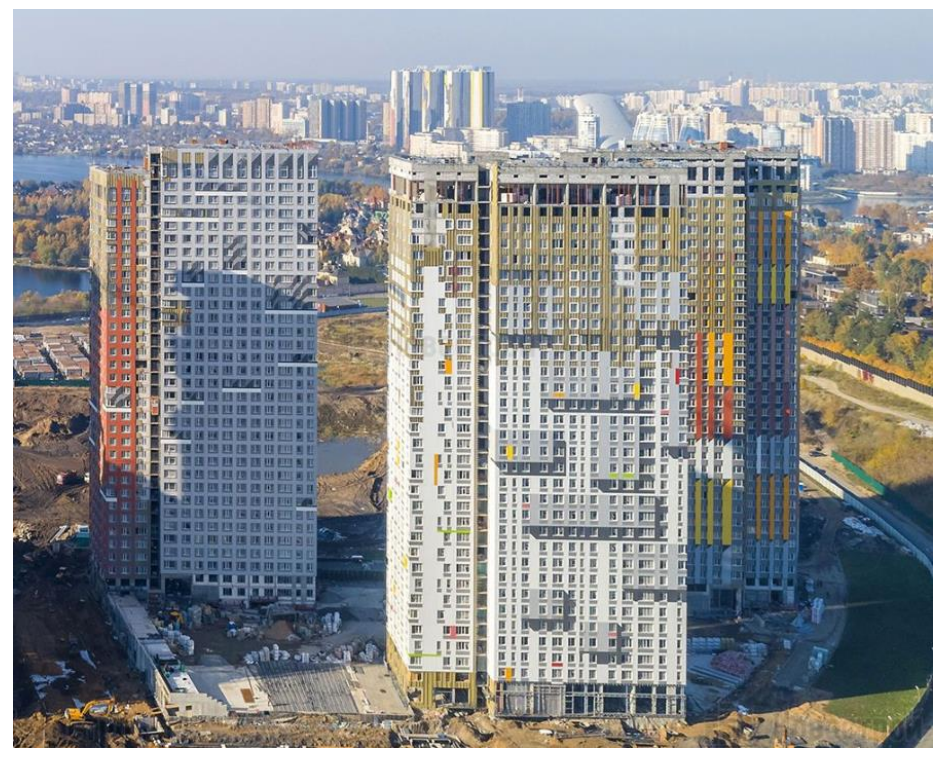

Fig. 2. Apartment complex under construction

\section{Geometric characteristics of hollow core slabs}

When constructing a hollow base plate, cube liners were used, forming a system of ribs in 2 directions.

Table 1. Characteristics of hollow core slab

\begin{tabular}{|c|l|c|}
\hline No. & \multicolumn{1}{|c|}{ Slab element } & Dimensions \\
\hline 1 & Height of voids & $600 \mathrm{~mm}$ \\
\hline 2 & Slab thickness & $1000 \mathrm{~mm}$ \\
\hline 3 & Thickness of bottom flange & $200 \mathrm{~mm}$ \\
\hline 4 & Thickness of top flange & $200 \mathrm{~mm}$ \\
\hline 5 & Thickness of the wall between voids & $200 \mathrm{~mm}$ \\
\hline
\end{tabular}

\section{Calculation}

The calculation of the base plate was carried out in the software package SCAD Office (version 21.1).

The slab itself, the pylons and walls of the stylobation of the lower floor were modeled, and the load from the entire building was already assigned to them.

The main task was to compare the precipitation, plot of moments and the percentage of reinforcement in the two options for the design of plates. 


\subsection{The calculation of the monolithic slab}

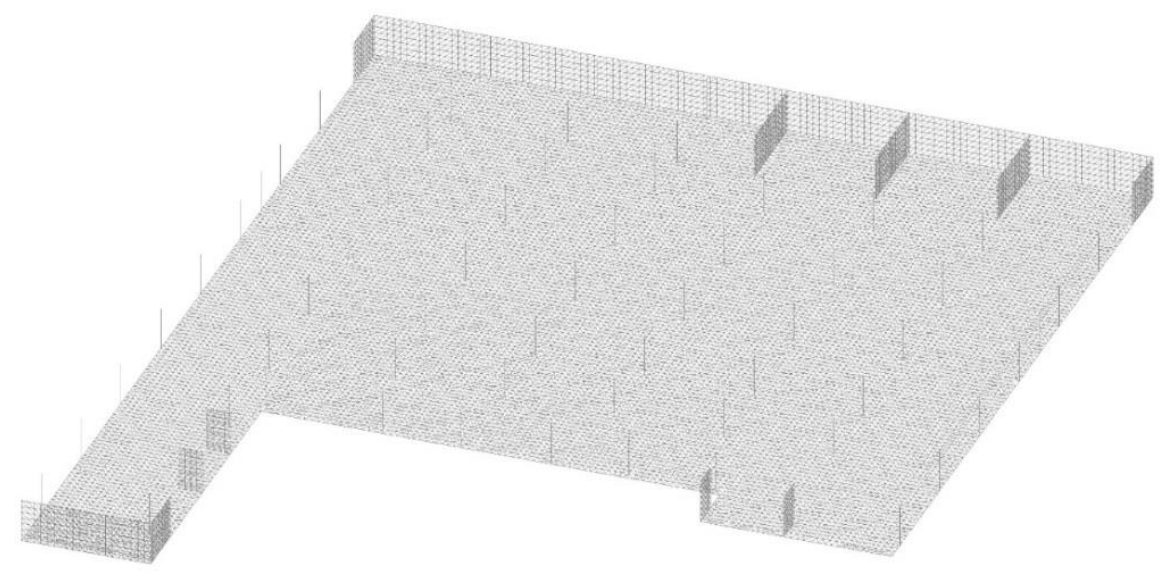

Fig. 3. Calculation scheme

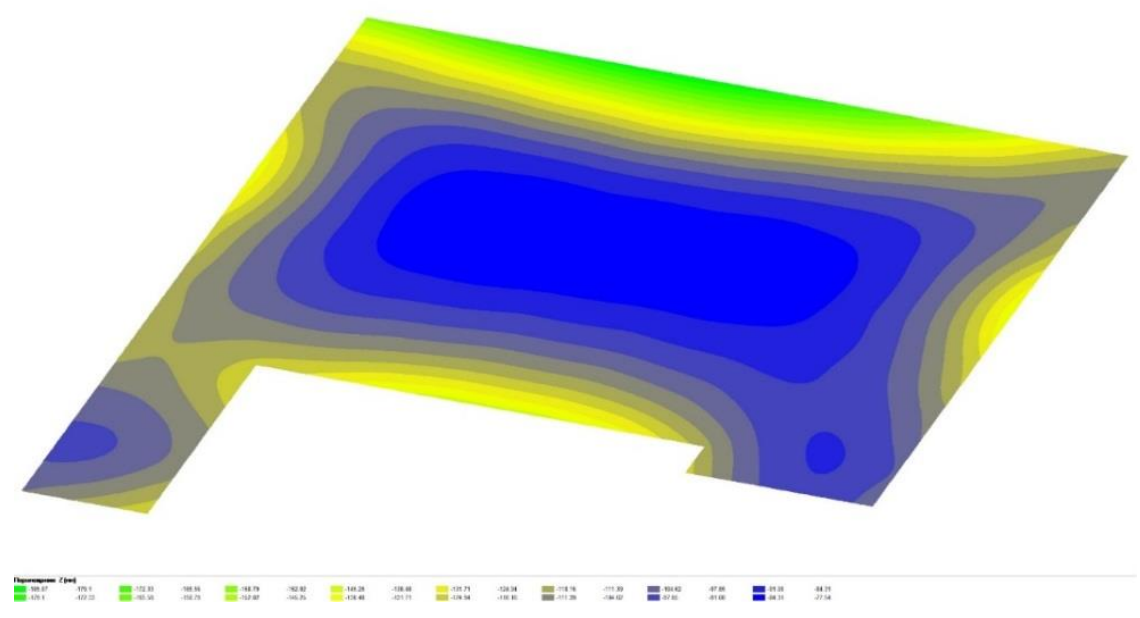

Fig. 4. Plots of displacement along the $\mathrm{Z}$ axis 


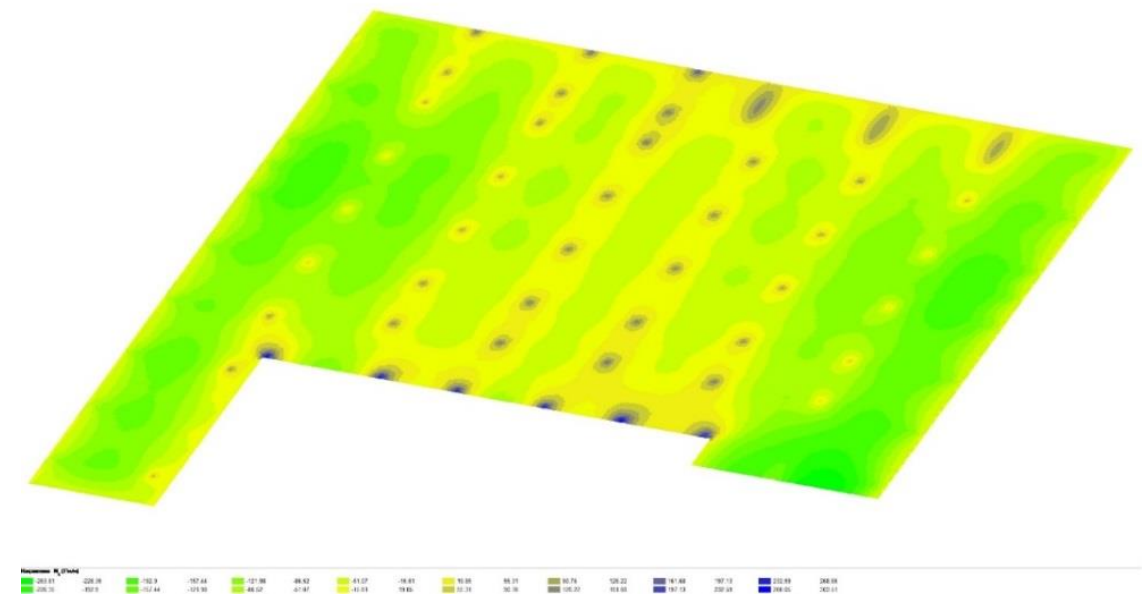

Fig. 5. Plot of Moments Mx

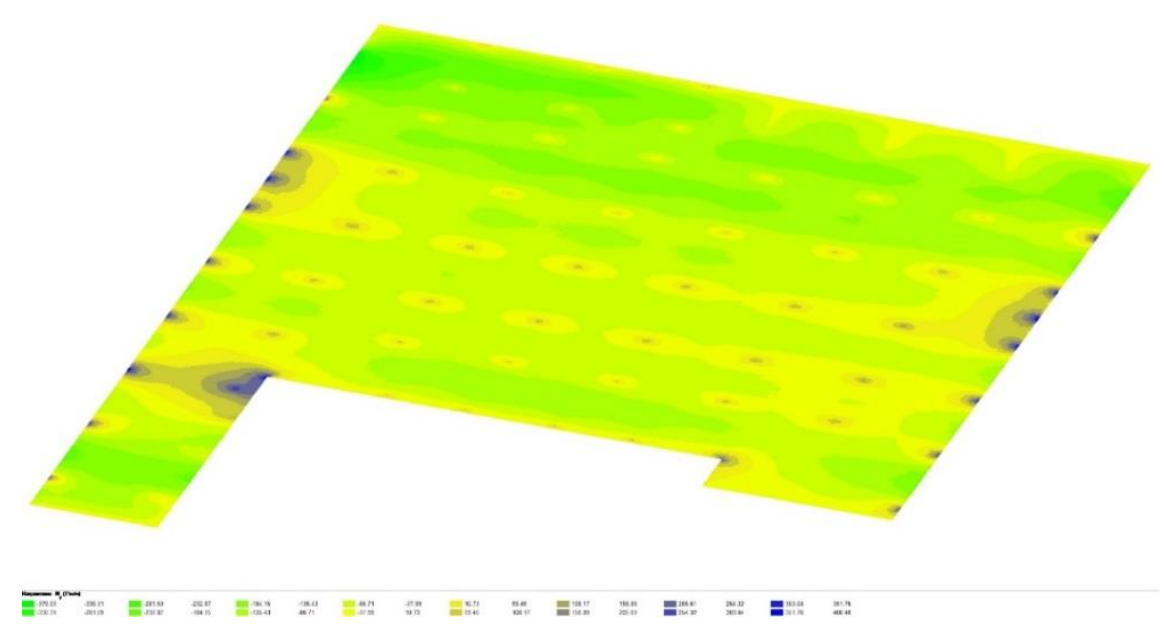

Fig. 6. Plot of moments My 


\subsection{Calculation of hollow-core monolithic slab}

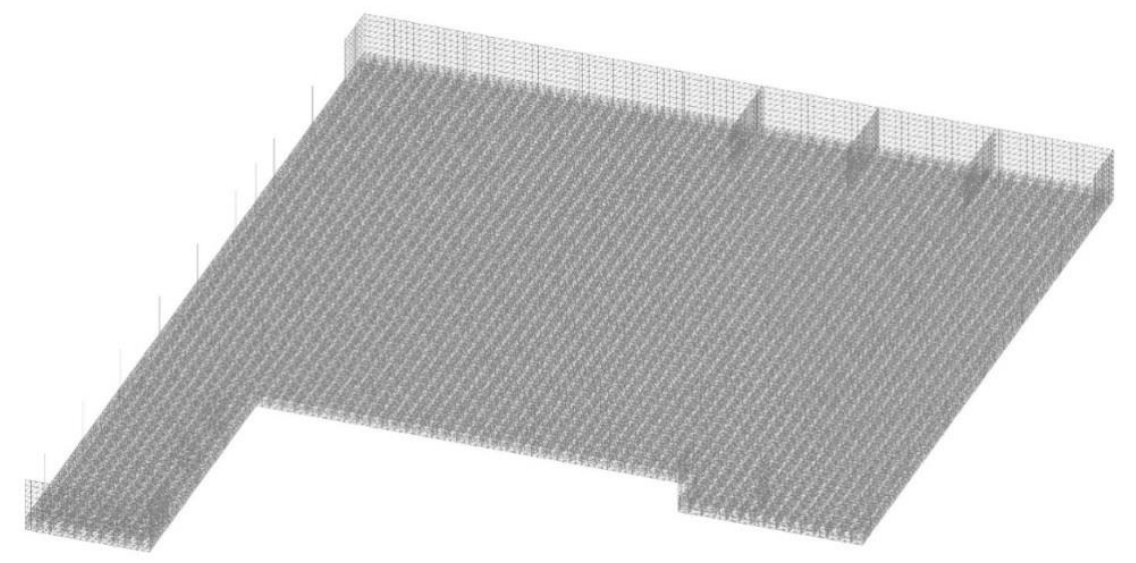

Fig. 7. Calculation scheme

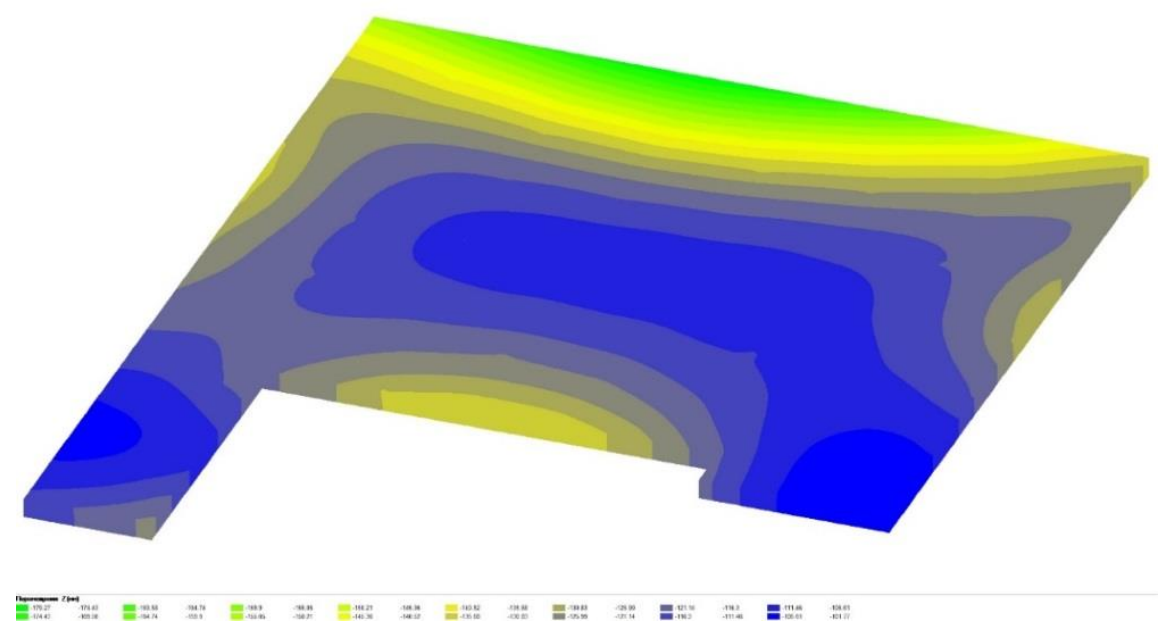

Fig. 8. Plot of Z Movements 


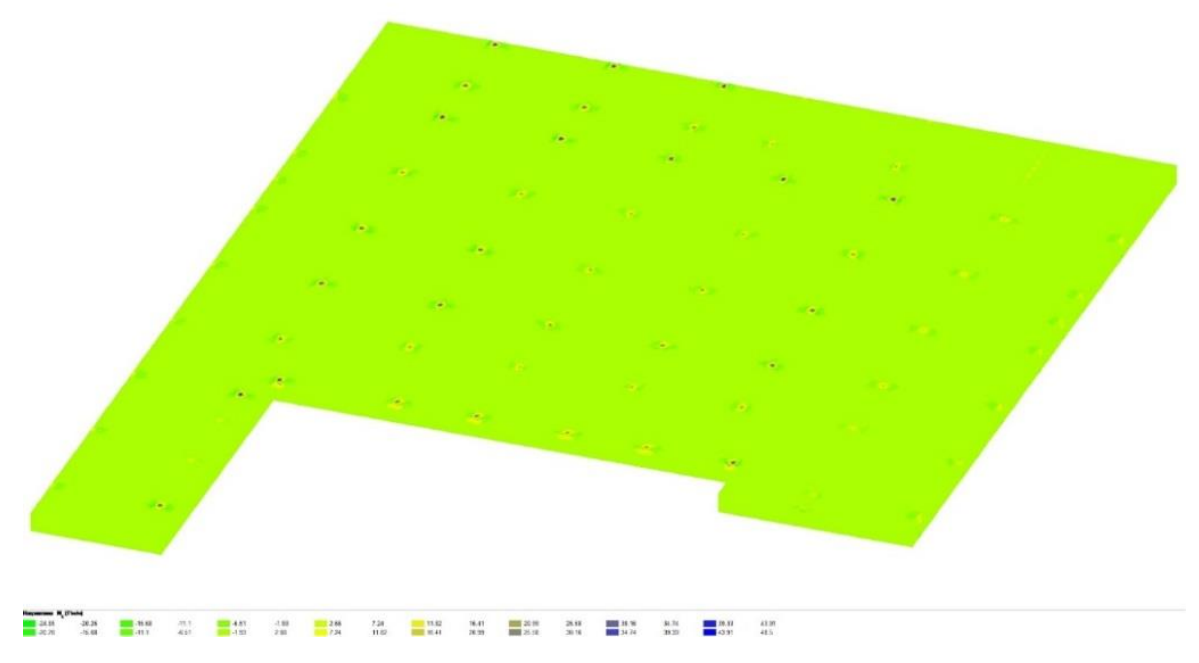

Fig. 9. Plot of Moments Mx

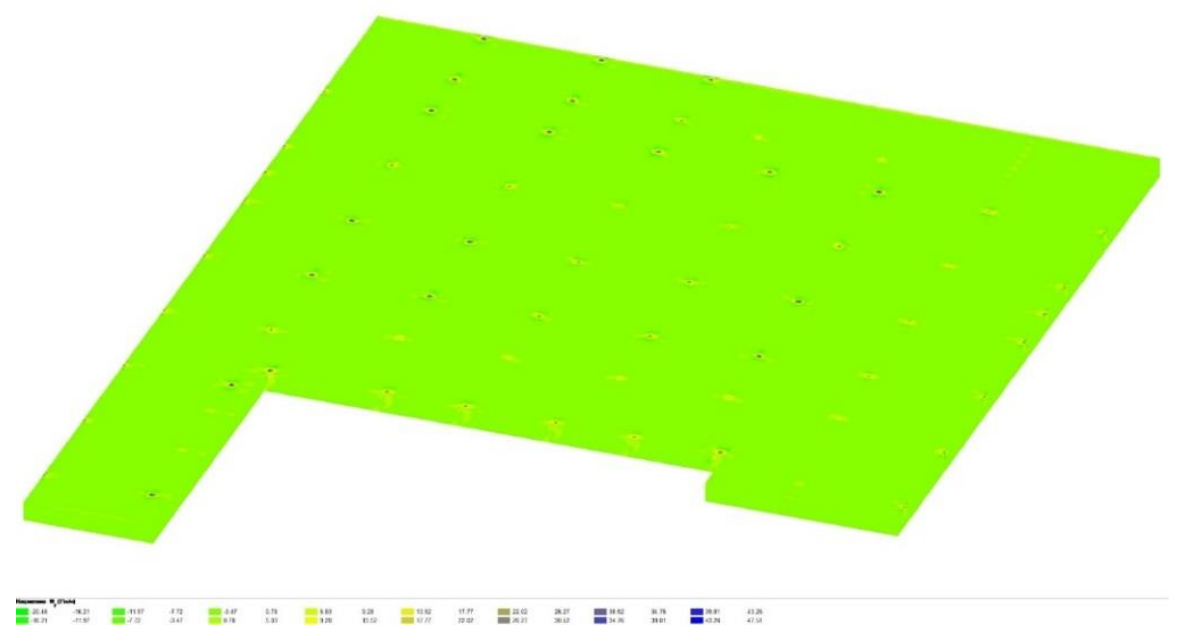

Fig. 10. Plot of Moments My

\section{Findings}

The results of calculations are shown in table 2

Table 2.

\begin{tabular}{|c|c|c|}
\hline Characteristics & Monolithic slab & Hollow-core monolithic slab \\
\hline \multirow{2}{*}{ Z-axe motion } & Max $-185,87 \mathrm{~mm}$ & Max $-179,27 \mathrm{~mm}$ \\
& Min $-84,31 \mathrm{~mm}$ & Min $-106,61 \mathrm{~mm}$ \\
\hline \multirow{2}{*}{ Epure Mx } & Max $-268,05 \mathrm{~T}^{*} \mathrm{~m} / \mathrm{m}$ & Max $-43,91 \mathrm{~T}^{*} \mathrm{~m} / \mathrm{m}$ \\
& Min $-263,81 \mathrm{~T}^{*} \mathrm{~m} / \mathrm{m}$ & Min $--24,85 \mathrm{~T}^{*} \mathrm{~m} / \mathrm{m}$ \\
\hline \multirow{2}{*}{ Epure My } & Max $-351,76 \mathrm{~T}^{*} \mathrm{~m} / \mathrm{m}$ & Max $-43,26 \mathrm{~T}^{*} \mathrm{~m} / \mathrm{m}$ \\
& $\operatorname{Min}--379,03 \mathrm{~T}^{*} \mathrm{~m} / \mathrm{m}$ & Min $--20,46 \mathrm{~T}^{*} \mathrm{~m} / \mathrm{m}$ \\
\hline
\end{tabular}


Concrete savings were $22,3 \%$, reinforcement- $5 \%$

The calculation showed that the main savings in the use of core drivers fell on concrete, while the volume of reinforcement decreased slightly.

This work was financially supported by Ministry of Science and Higher Education of the Russian Federation (\#NSh-3492.2018.8).

\section{References}

1. R. Zaliger, Reinforced concrete, its calculation and design

2. D. A. Glotov, I. S. Loskutov, O. V. Kantur, Monolithic hollow floors in building construction

3. SP 63.13330.2012. Concrete and won concrete construction

8. Design requirements

4. SP 22.13330.2016. Soil bases of buildings and structures

5. S. B. Ukhov, V. V. Semenov, V. V. Znamensky, Z. G. Ter-Martirosyan, S. N. Chernyshev, Soil mechanics, bases and foundations, (1994)

6. D. U. Chunyuk. Risk management in solving geotechnical problems of construction of high-responsibility structures, (2009)

7. D. U. Chunyuk, V. G. Koz'modemyanskiy, O. V. Kopteva, Identify the risks when carrying out compaction of soils by heavy rammers

8. GOST R 54257-2010. Reliability of constructions and foundations. Basic principles and requirements

9. GOST 25100-2011. Soils. Classification

10. R. A. Mangushev, V. D. Karlov, I. I. Sakharov, Soil mechanics, 256 (2015) 